\title{
Consequence Modelling and Analysis of Methane Explosions: A preliminary Study on Biogas Stations
}

\author{
Müge Ensari Özay ${ }^{1, *}$, Pelin Güzel², Emine Can $^{3}$ \\ ${ }^{1}$ Department of Occupational Health and Safety, Faculty of Health Sciences, Üsküdar University, Istanbul, Turkey \\ ${ }^{2}$ Faculty of Engineering and Natural Sciences, Istanbul Medeniyet University, Istanbul, Turkey \\ ${ }^{3}$ Department of Physics Engineering, Faculty of Engineering and Natural Sciences, Istanbul Medeniyet University, Istanbul, Turkey
}

\begin{abstract}
Article History
Received: $\quad 30.10 .2019$

Accepted: $\quad 03.02 .2021$

Published: $\quad 20.03 .2021$

Research Article

Abstract - Biomass is one of the most important sources of renewable energy. Biomass resources can be utilized by producing biogas in the biogas stations, which include process equipment operating in critical conditions. In this study, a consequence analysis of a methane gas explosion carried out to estimate the explosion and the toxic threat zones of a biogas station in Turkey. ALOHA and PHAST Software Tools are used to realize an explosion by modelling scenarios and thus to estimate the effects of an explosion just to get an insight on methane gas explosion. By using ALOHA software, two different scenarios as leakage from the biogas tank and flammable chemical escaping directly into the atmosphere are designed and calculated by the Gaussian model. In addition to that, two different explosion scenarios as a leakage scenario from the biogas storage tank and a catastrophic rupture scenario are computed by using the PHAST Software. According to the first scenario results from ALOHA, explosions can cause destruction of buildings, serious injuries and shattering of glasses in the threat zones about $200 \mathrm{~m}$ while in the second scenario only shattering of glasses can be seen in $22 \mathrm{~m}$ of threat zone. The results from the PHAST show that threat zones do not change significantly at different weather conditions. It is found that the catastrophic rupture has maximum hazard zone limits among all the scenarios. It has been concluded that using different model-based software can be useful to understand possible results of biogas plant explosions.
\end{abstract}

Keywords - ALOHA software, biogas storage tank, explosion, methane gas, occupational health and safety, PHAST software,

\section{Introduction}

Biogas is one of the most important renewable energy in the world. In biogas production plants, organic wastes have been processed and produced electrical energy. The European Biomass Association evaluates that Biomass-based energy in Europe can be increased from 72 million tons in 2004 to 220 Million tons in 2020 (Kotek et al. 2015). The Biogas production amount from animal fertilizer in Turkey is around 3.5 billion m3/year (Arıkan, 2008; Köse, 2017). Today, Turkey has eighty-five build biogas plants, however, only thirtysix of them are in-service in several geographical locations. Some of these power plants having higher energy productions are Odayeri Landfill Gas Plant (Istanbul, $34 \mathrm{MW}$ ), Mutlular Biomass Energy Plant (Balıkesir, 30 MW), Mamak Landfill Biogas Plant (Ankara, 25 MW), Çadırtepe Biomass Plant (Ankara, 23MW), Sofulu Landfill Biogas Plant (Adana, 16MW), ITC Antalya Biomass Plant, (Antalya, 14MW), Kömürcüoda Landfill Biogas Plant (İstanbul, 14MW) (Bilici, 2019).

\footnotetext{
1 (1D müge.ensariozay@uskudar.edu.tr

2 (1D) pelin.guzel@medeniyet.edu.tr

3 (1D) emine.can@medeniyet.edu.tr

*Corresponding Author
} 
As the number of biogas stations increases, the number of accidents increases in biogas units. More than 800 accidents occurred after 2005 among 13,171 European biogas stations (Kotek et al. 2015). Casson et al., (2016) created a database of 169 biogas accidents and the study showed that almost $12 \%$ of the past accident analysed can be classified as major accidents. According to the geographical distribution of 169 accidents, $96 \%$ of the accidents happened in Europe (163 over 169), most of the events took place in Germany (76\%), while a lower amount were documented in France (11\%), Italy (6\%), and UK (2\%) (Casson et al., 2016).

Generally, chemical accidents can be divided into toxic chemical leaks and explosions caused by fires (Davis, 2014; Krentowski, 2019; Lee, 2019; Okho, 2013). The reasons of biogas plant accidents are identified as five categories: a) leakage in the storage tank and/or in the distribution pipes of the biogas plant, b) fire and explosion as a result of $\mathrm{CH}_{4}$ leakage, c) release of $\mathrm{H}_{2} \mathrm{~S}$ from septic waste, d) high pressure inside the digester due to overflow or freezing of valves, e) environmental contamination by the release of effluent discharge (Kotek et al. 2015). Wang (2017) establishes a leakage risk monitoring and early-warning model for an anaerobic reactor of a biogas station by using modelling software. When an accident happens, its consequences are considered by its destructive force, as well as direct and indirect losses (Zhang.2019). To reveal and reduce the consequences and the potential damage of explosions, researchers have focused on the flammable gas explosions (Amyotte, 2017; Lv, 2017). Several studies are modelling the consequences of fire, explosion and toxic dispersion by using different tools like PHAST (Process, Hazard, Analysis, Software Tool), ALOHA (Areal Locations of Hazardous Atmospheres, U.S. Protection Agency) and FLACS (Flame Acceleration Software) modelling programs (Dadashzadeh, 2013; Dasgotra, 2018; Hasani, 2016; Inanloo, 2015; Zareei, 2016). PHAST is one of the mostly used process hazard analysis software for process safety management in both design and operation parts. This software is outstanding with its wide applicability of process hazard analysis tool including various release types such as from leaks, pipework, pipelines, ruptures etc. The models in the software are extensively validated especially for process industry hazards. It is also possible to define different hazard types as explosions, fires, toxics and flammable, consider directional environmental effects such as wind or surface roughness. By using this software, exclusion zones and safe distances can be easily defined. ALOHA is another hazard modelling software which is widely used to get an insight on chemical/hazardous material emergencies. It is an open source program and available from the internet site (EPA, 2017). Properties of real or potential chemical/hazardous materials are given as an input to the software and threat zone estimates for different scenarios of hazards can be estimated. Toxic gas clouds, flammable gas clouds, jet fires, pool fires and vapour cloud explosions can be modelled. In the given results, the red threat zone indicates the worst hazard level while the orange and yellow threat zones show the decreasing hazard zones.

In this study, the findings from the PHAST and ALOHA software are compared and combined to get an insight on health and safety problems occurred due to an explosion in a biogas station. In the literature, there are various studies including consequences analysis of hazardous chemicals by using PHAST and ALOHA software. Pandya et al. (2008) studied by the Fourier Amplitude Sensitivity Test to carry out a parametric sensitivity analysis of PHAST atmospheric dispersion modelling for an accidental toxic gas dispersion scenario. They studied the relative influence of uncertainty in independent input parameters on the variation of the model outputs. Several studies are also carried out by using ALOHA to be able to understand the threat of a chemical leakage to the residents in neighbouring area, air quality and occupational safety (Tseng et al., 2012). Tseng and co-workers (2012) investigated the dispersion of three important substances (chlorine, epichlorohydrin and phosgene) due to their critical threat to safety. By using ALOHA software, they were able to discover the threat zones, which demonstrate the scales of a toxic chemical release impact, in three different production plants in Taiwan. In another research, Çetinyokuş (2017) studied consequences analysis of hazardous chemicals which were flammable substance (methane), toxic liquid (ethylene diamine) and toxic gas (methyl chloride) by ALOHA software, and found that atmospheric options, especially wind speed, atmospheric stability class and ground roughness, had significant effects on the effect distances within the 
threat zones for the selected three hazardous chemicals. Moreover, Trávnícek et al. (2018) examined flare stacks on agricultural biogas plants by ALOHA software, and they found that the methane gas will be diluted more quickly at higher levels than ground level. Recently, Dou and co-workers (2020) evaluate the methane fraction on explosion characteristics of biogas/air mixture in a duct, and found that the PVC film thickness affected the explosion overpressure more, whereas the methane fraction in biogas affected the flame velocity.

Comparison of findings from both ALOHA and PHAST software and additionally Computational Fluid Dynamics (CFD) method is also carried out by various studies. Similarly, to the publications mentioned above, a consequence analysis is carried out for the storage tank of n-Butanol and its release from the tank by ALOHA (Bhattacharya \& Kumar, 2015). In this work, the results are also compared with the PHAST software findings. It is suggested that PHAST results seem to be more realistic but the difference between the results are in an acceptable range as $\pm 10 \%$. It is also possible to evaluate flammability and explosiveness of a stored chemical compound by ALOHA. Derychova and Bernatik carried out a study based on the risk assessment of biogas plants and designed accident scenarios including fire and explosion of biogas mixture in which methane is the major compound (Derychova \& Bernatik, 2016). The first scenario is the pipeline leaking from the tank and methane is burning as a jet fire. The results indicate that the affected area is $35 \mathrm{~m} 2$ including lethal zone, zone of 2nd degree burns and zone of injuries. In the second scenario, methane leakage occurs by the leak pipe and leaking methane is not ignited. These two scenarios are mentioned as possible leaks from a biogas tank and the results are critical to diminish the rate of accidents. Carboni and co-workers are investigated the accidental release of several biogas mixtures resulting in flash fire and toxic cloud dispersion and modelled by PHAST and CFD software ANSYS Fluent (Carboni et al., 2020). Here, PHAST software and CFD approach are compared. Even the findings of CFD calculations are reliable by including a much more realistic approach, implementation of plant geometry brings higher computational cost than PHAST.

Biogas is a general term of gas produced by anaerobic fermentation in an organic waste. It is necessary to know the percentage of biogas in a station to model the explosion limits. Although the composition of biogas depends on the introduced organic materials and the process conditions on the biogas station, raw biogas mainly consists of methane (50 mol\% to $80 \mathrm{~mol} \%$ ), carbon dioxide (20 mol\% to $50 \mathrm{~mol} \%)$, water vapour (0 mol\% to $12 \mathrm{~mol} \%$ ), nitrogen ( $0 \mathrm{~mol} \%$ to $5 \mathrm{~mol} \%$ ), oxygen ( $0 \mathrm{~mol} \%$ to $2 \mathrm{~mol} \%)$, hydrogen sulfide $(0.01 \mathrm{~mol} \%$ to $0.04 \mathrm{~mol} \%$ ) and traces of ammonia, hydrogen and higher hydrocarbons (Schoder et al. 2014). The design and technology of biogas plants differ according to the size, function, location, and feedstock of biomass. The biogas stations can be classified as a) family-scale biogas plants (very small scale), b) farm-scale biogas plants (small or medium to large scale), c) centralized/ joint co-digestion plants (medium to large scale) ( $\underline{\text { Al Seadi, }}$ 2008). Biogas production is expected to be stable and constant. However, inside the digester, biogas is formed in fluctuating quantities and the demand for biogas can vary during the day. To ensure stable biogas utilization, various types of storage facilities are available. Generally, for industrial type, larger biogas plants, separate external biogas storage tanks are established, and these types of pressurized tanks are made of steel and have pressures between 5 and 250 bar (Al Seadi, 2008). The hazards that may occur as a result of a possible accident and explosion in a biogas plant will change according to its technology and design.

The aim of this study is to analyse the explosion and toxic effects due to potential accidents in a large-scale industrial type biogas station. A large-scale biogas station is chosen to be modelled, since the explosion of such a station will be more destructive than the others. For this purpose, two different modelling programs as ALOHA and PHAST software tools are used to simulate two different scenarios in a biogas plant; a leakage scenario from a biogas tank and flammable chemicals escaping directly into the atmosphere. The properties of a biogas storage tank and its environment are given as inputs to the software. Since major component of a biogas mixture is methane, the calculations are carried out assuming the only component is methane in the tank. Afterward, the explosion hazards of a methane storage tank in a large-scale biogas station are examined. 


\section{Materials and Methods}

In this research, the explosion hazards of an external methane storage tank in a large-scale biogas station are demonstrated by two different modelling programs. ALOHA version 5.4.7 Software and PHAST version 7.2 are used to predict different explosion scenarios and thus to estimate the effects of a methane gas explosion.

\subsection{ALOHA Software}

ALOHA is a computer modelling tool to estimate the movement and dispersion of hazardous chemical gases, and to predict the rates at which gases may escape into the atmosphere from broken gas pipes, leaking tanks, and evaporating puddles, and hazardous gas cloud dispersion to the atmosphere after an accidental chemical release (EPA, 2017). ALOHA can also be used to predict the area where a flammable gas may explode by using the physical characteristics of the released chemical and the real-time circumstances of the release scenario to predict the dispersion of a hazardous gas cloud.

ALOHA software can evaluate the consequences of explosion and atmospheric releases of chemical species parameters by selection of meteorological conditions, rural and urban areas etc. Graphical outputs include a "threat zone" that can be plotted on maps with MARPLOT to display the location of other facilities storing hazardous materials and vulnerable locations (EPA, 2017).

ALOHA provides for the source options as direct, puddle, tank, or pipe. Puddle option is selected when the source is a liquid puddle of constant radius. The liquid can be either a normal evaporating liquid, or a boiling liquid. Tank option is selected when the source is a horizontal or vertical cylinder, or a spherical tank at ground level with a single hole. The tank initially contains a gas, a liquid, or a liquefied gas. The contents can change phase as a result of temperature and/or pressure changes. Pipe option is selected when the source is a pressurized pipe containing gas with a single hole at ground level. The direct source is a point release and can be either a continuous emission of rate or an instantaneous release of total mass. For a direct release type as instantaneous or continuous release, total mass, mass flow rate, and source height must be provided (Bhattacharya and Kumar, 2015).

As mentioned above, very detailed description of input properties are given to the software. However, there are some limitations of the software: i. It assumes that the chemical compound is mixed with air as an immediate process, ii. It has no capability to detect the end products, i.e. smoke, particulate matter, radioactive particles. iii. It assumes that the wind speed and wind direction are constant during the simulation run (Yadav et al., 2020).

\subsection{PHAST Software}

PHAST is a comprehensive hazard analysis package and investigate a chemical process incident from initial release through formation of a cloud or pool to final dispersion calculating concentration, fire radiation, toxicity and explosion overpressure, and catastrophic rapture regions in 3D (Naemnezhad et al., 2017).

PHAST software can consider the interaction of the flammable cloud and identified of congestion by using TNT equivalency model (Mannan, 2012), or the Multi-Energy model (Van den Berg, 1985) or Baker Strehlow Tang model (Baker et al., 1996).

PHAST generates blast parameters for overpressure and display as contours or in tabular reports and develop combined hazard contours in the explosion modelling software for a range scenarios and hazard types as explosions, fires, toxics and flammable clouds. The program takes into account the directional aspects that can influence the explosion modelling outcome like wind or surface roughness (DNV GL, 2018). 
In PHAST there are limitations in the handling of dispersion modelling for an instantaneous leak. In this case, the vapour dispersed from the tank would be added into the very small instantaneous cloud and the dispersion results would demonstrate the properties of an instantaneous cloud. In order to model a continuous leak, the series of representative vaporization segments are used (DNV GL., 2018).

\subsection{Case Study}

ALOHA and PHAST software programs are used as risk modelling tools and designed to assess the development of potential accidents, from the initial leak point, the spread of the hazardous substance, to analyse the explosion and toxic effects. Two different scenarios are evaluated by the Gaussian model for predictions by using ALOHA Software: a) a leakage scenario from biogas tank, b) flammable chemical escaping directly into the atmosphere. In addition to that, two different explosion scenarios are run by PHAST Software Tool a) a leakage scenario from a biogas storage tank, b) a catastrophic rupture scenario.

These software contain several important critical input items to analyse the outcome modelling of accident scenarios. One of the most critical input parameters is represented by weather conditions. Meteorological stability, seasonal temperatures, humidity, wind speed and direction play a very important role in modelling such accidents. In case of ALOHA program, wind speed is selected as 2 meters/second and from South to West. Cloud cover is partly cloudy. The air temperature is $25^{\circ} \mathrm{C}$. Stability class selected as B. In case of PHAST program, three different weather conditions are chosen as $2 \mathrm{~F}, 2 \mathrm{~B}$ and $2 \mathrm{D}$. $2 \mathrm{~F}$ indicates that wind speed is 2 $\mathrm{m} / \mathrm{s}$, and stability class is $\mathrm{F}$ means night-time conditions moderate cloudiness and light/moderate wind. $2 \mathrm{~B}$ shows that wind speed is $2 \mathrm{~m} / \mathrm{s}$, and stability class is B means solar insolation is moderate and windy. 2D displays that wind speed is $2 \mathrm{~m} / \mathrm{s}$, and stability class is D shows a little sun and high wind overcast or windy night.

Additionally, risk assessment is largely influenced by the amount and type of material involved, which is also an important factor in the calculation of accidents. As shown in Table $\underline{1}$, in both Software, the biogas storage tank contains methane gas at a pressure of $15 \mathrm{bar}$ and a temperature of $25^{\circ} \mathrm{C}$. The tank is made of steel with a $10 \mathrm{~m}$ diameter and $12.70 \mathrm{~m}$ length. The results of the three modelling programs are presented in graphical forms. 
Table 1

Input Data of ALOHA and PHAST Programs

\begin{tabular}{lll}
\hline Parameters & ALOHA Data & PHAST Data \\
\hline Local Information & Turkey, Istanbul & Turkey, Istanbul \\
$\begin{array}{l}\text { Building type / Type of terrain for } \\
\text { dispersion }\end{array}$ & $\begin{array}{l}\text { Single storage, unsheltered } \\
\text { surroundings }\end{array}$ & Land \\
Material & Methane gas & \\
Tank type & Pressurized cylindrical vessel & Methane gas \\
Tank diameter & $10 \mathrm{~m}$ & $10 \mathrm{~m}$ \\
Tank length & $12.73 \mathrm{~m}$ & $12.73 \mathrm{~m}$ \\
Tank Volume & $1000 \mathrm{~m}^{3}\left(700 \mathrm{~m}^{3}, 70 \%\right.$ full $)$ & $1000 \mathrm{~m} 3\left(700 \mathrm{~m}^{3}, 70 \%\right.$ full) \\
Mass of compound & $437 \mathrm{~kg}(70 \%$ full $)$ & $437 \mathrm{~kg}(70 \% \mathrm{full})$ \\
Wind speed, direction / Stability & $2 \mathrm{~m} / \mathrm{s} \mathrm{South} \mathrm{to} \mathrm{West} \mathrm{/} \mathrm{B}$ & $2 \mathrm{~F}, 2 \mathrm{~B}$ and $2 \mathrm{~F}$ \\
Class & & \\
Measurement height & $3 \mathrm{~m}$ above ground & $3 \mathrm{~m}$ above ground \\
Ambient Temperature & $25^{\circ} \mathrm{C}$ & $25{ }^{\circ} \mathrm{C}$ \\
Humidity & $\% 50$ & $\% 50$ \\
Temperature inside tank & $25^{\circ} \mathrm{C}$ & $25{ }^{\circ} \mathrm{C}$ \\
Tank Pressure & 15 bar & 15 bar \\
Leak type, dimension & Circular opening $25 \mathrm{~mm}$ & Circular opening $25 \mathrm{~mm}$ \\
\hline
\end{tabular}

\section{Results and Discussion}

\subsection{ALOHA Results}

In the ALOHA program, local information for a biogas tank source is chosen as Istanbul, Turkey. Building type is selected as single stored and unsheltered surroundings. Even though biogas is a mixture of gases, methane is selected as a pure chemical due to the limitations of the ALOHA program. ALOHA is designed to model the release and dispersion of pure chemicals and a few select solutions; the property information in its chemical library is not valid for mixtures of chemicals. Since the methane percentage in large scale biogas plants can reach up to $80 \%$, it was decided to use the ALOHA program.

Most of the biogas production plants are of small or medium scale, however the major accidents happened in large scale industrial type biogas stations. For this reason, a tank volume of $1000 \mathrm{~m}^{3}$ has been chosen. The region of this study was chosen as Istanbul because there are large-scale biogas power plants in Istanbul. In PHAST program, different wind speeds were selected in the study in order to analyse the results of toxic distribution and effects in more detail. Since the region was not selected in PHAST program, the results would not change if a different region was selected. However, in the ALOHA program, a region and city selection are made, and since ALOHA takes the wind situation of that region into account, the result would have changed if another location was selected.

Two different scenarios are run by the Gaussian model for predictions. The first one is a leakage scenario from a biogas tank. The second one is flammable chemicals escaping directly into the atmosphere. The atmospheric conditions envisaged for two of the scenarios are the same. Wind speed is selected as 2 meters/second and 
from South to West. Measurement height is $3 \mathrm{~m}$ above ground. Ground roughness is an open country. Cloud cover is partly cloudy. The air temperature is $25^{\circ} \mathrm{C}$. Stability class is automatically chosen according to date, time, weather conditions, and cloud cover and in these scenarios, it is selected as B. Inversion height option is selected as no inversion. Humidity is chosen $50 \%$ as a medium.

Scenario 1 is the leakage of gas from a biogas storage tank containing methane as a flammable gas. During the selection of tank type, the following parameters are given as output. The tank type is a vertical cylinder with $10 \mathrm{~m}$ diameter, $12.70 \mathrm{~m}$ length, $1000 \mathrm{~m}^{3}$ by volume. The tank contains methane gas-only and is $70 \%$ full. The temperature of the tank is at $25^{\circ} \mathrm{C}$. The internal tank pressure is $15 \mathrm{bar}$. Tank pressure unusually high alert is given. Release duration is limited at 1 hour and the maximum average sustained release rate is 45.9 kilograms/minute. The gas is leaking from the tank through a circular hole with a $25 \mathrm{~mm}$ diameter and the chemical is not burning as it escapes to the atmosphere. There are three major potential hazards from flammable chemical as it leaks from the tank; a.) Downwind toxic effects, b.) Vapour cloud flash fire, c.) Overpressure (blast force) from a vapour cloud explosion.

In case of the toxic effect area of the vapour cloud, the threat zone is not drawn because the effects of nearfield patch lines make dispersion predictions less reliable for short distances. In case of the flammable area of vapour cloud, Figure 1a shows that local areas of flame can occur even though the average concentration is below the lower explosion level (LEL). ALOHA finds the flammable area by using $60 \%$ and $\% 10$ of the LEL $25 \mathrm{~m}$ and $62 \mathrm{~m}$, respectively. Figure $\underline{1 b}$ shows the blast area of vapour cloud explosion. The time of vapour cloud ignition is selected as unknown and the vapour cloud is ignited by detonation. The level of congestion is chosen as difficult to walk through (e.g. pipe rack, dense forest). When the overpressure is greater than 8.0 psi, the (red) area with 74 meters' diameter is affected by the destruction of buildings. As the overpressure is greater than $3.5 \mathrm{psi}$, the (orange) area with 97 meters' diameter is caused by serious injury likely. At the time the overpressure is greater than $1.0 \mathrm{psi}$, the (yellow) area with 184 meters is affected like shattering glasses.

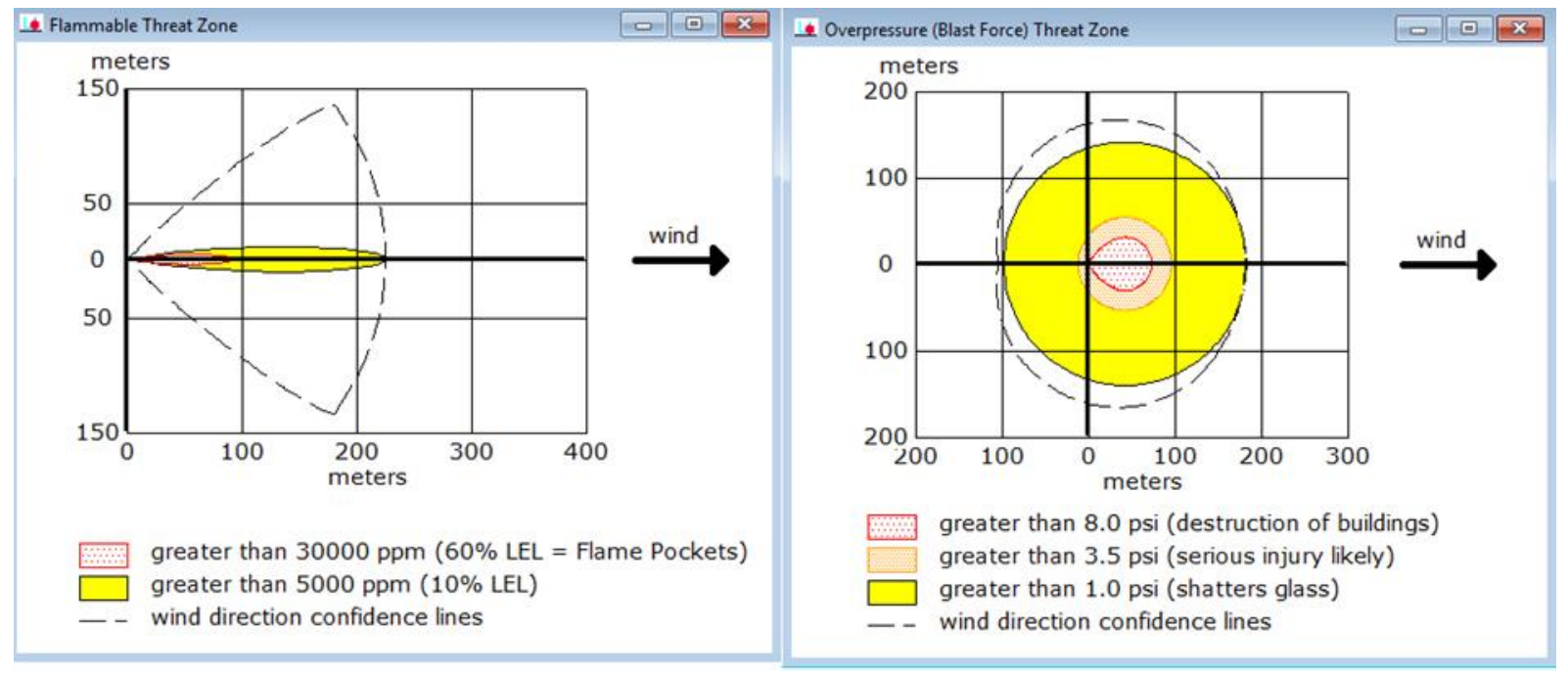

Figure 1. a) Flammable Threat Zone Overpressure, b) Overpressure (Blast Force) Threat Zone for Scenario 1 by ALOHA

Scenario 2 is flammable chemical (methane gas) escaping directly into the atmosphere and the chemical is not on fire. The source height is zero. Release duration is limited at 1 hour and the maximum average sustained release rate is 45.9 kilograms/minute. There are three major potential hazard scenarios; a.) Toxic area of the vapour cloud, b.) Flammable area of the vapour cloud, c.) Blast area of vapour cloud explosion. Figure $\underline{2 a}$ shows the toxic threat zone in terms of public exposure guideline system like PAC. The maximum distance for PAC-1, PAC-2 and PAC-3 is 52 m., 69m., and 130m., respectively. Figure $2 \underline{b}$ presents the flammable threat 
zone. Local areas of flame can occur even though the average concentration is below the LEL. The simulation finds the flammable area of vapour cloud by using $60 \%$ of the LEL as red 271 meters $(30000 \mathrm{ppm}=60 \%$ LEL $=$ Flame Pockets) and $\% 10$ of the LEL as yellow 600 meters $(5000 \mathrm{ppm}=10 \%$ LEL). Figure $2 \mathrm{c}$ demonstrates the blast force threat zone ignited by spark or flame. The LOC values on red and orange regions do not exceed, so the destruction of buildings or serious injury likely will not happen in this scenario. However, the yellow region shows that an effect like shattering glasses observed in an area of 22 meters' diameter.

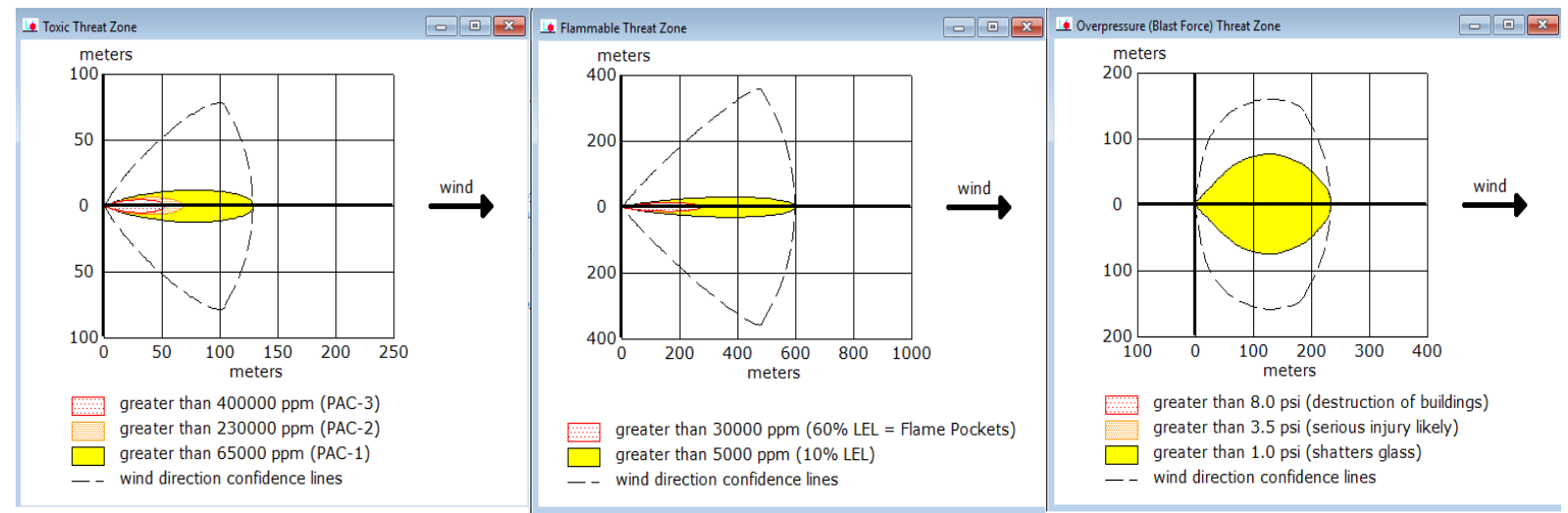

Figure 2. a) Toxic Threat Zone; b) Flammable Treat Zone; c) Overpressure (Blast Force) Treat Zone for Scenario 2 by ALOHA

\subsubsection{Effect of Ambient Temperature and Wind Speed Analysis}

The extreme weather conditions are also considered by ALOHA software in order to understand the effect of these conditions on the explosion results. For this purpose, the worst weather conditions in the last 90 years are gathered from Turkish State Meteorological Service. The investigated weather conditions are given in Supplementary Materials.

The wind speed is taken as about $32 \mathrm{~m} / \mathrm{s}$ as a worst case of wind speed found in the reference of Turkish State Meteorological Service. In all calculations tank temperature are given as $25^{\circ} \mathrm{C}$. The findings indicated that threat zone of vapour cloud is less than $10 \mathrm{~m}$. Flammable area of vapour cloud seems to be depended on the ambient weather condition and ranging between $11 \mathrm{~m}(30000 \mathrm{ppm})-31 \mathrm{~m}(5000 \mathrm{ppm})$. In all four lowest temperature values no explosion is predicted. However, for the highest temperature conditions the explosion might cause to shatter glasses less than 10 meters of the tank. The findings show that a change in the extreme ambient temperature values might not cause significant difference in the threat zone and flammable area.

\subsection{PHAST Results}

In this study, two different explosion scenarios are designed by PHAST Software Tool. The first one is a leakage scenario from the biogas storage tank. The second one is a catastrophic rupture scenario. The biogas storage tank is chosen as a pressurized vessel filled by methane gas. Three different weather conditions are chosen as $2 \mathrm{~F}, 2 \mathrm{~B}$ and $2 \mathrm{D}$.

Scenario one is a leakage scenario from the biogas storage tank. Figure $\underline{3 a}$ demonstrates the maximum radiation at $8.04 \mathrm{~m}$ with an intensity of $44.64 \mathrm{~kW} / \mathrm{m}^{2}$. Figure $\underline{3 \mathrm{~b}}$ shows the explosion worst-case radii for dispersion at downwind distance as $29.50 \mathrm{~m}, 28.41 \mathrm{~m}$ and $28.78 \mathrm{~m}$ at category $2 \mathrm{~F}$, category $2 \mathrm{~B}$ and category $2 \mathrm{D}$ respectively. Even the category $2 \mathrm{~F}$ has the worst case, the values are very close to each other. 

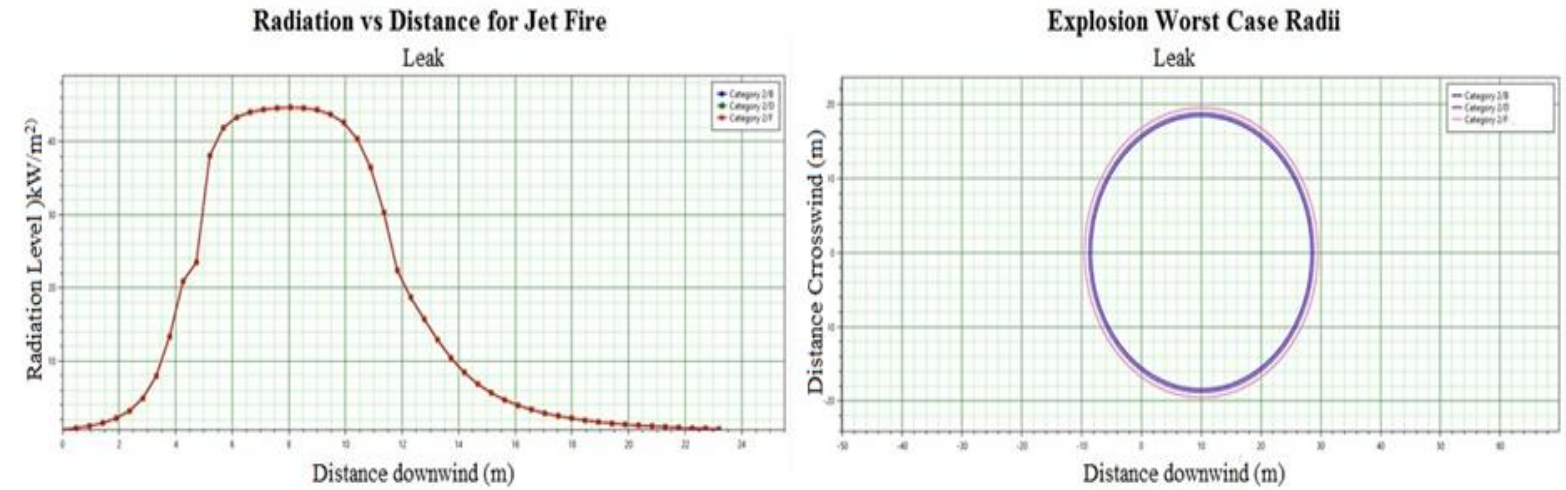

Figure 3. a) Radiation distance for fireball; b) the explosion worst-case radii for dispersion at downwind distance

Scenario two is a catastrophic rupture scenario. Figure $\underline{4 a}$ displays a maximum cloud footprint in case of catastrophic rupture at three different categories as category $2 \mathrm{~F}\left(5.072 \mathrm{~m}^{2}\right)$, category $2 \mathrm{~B}\left(4.926 \mathrm{~m}^{2}\right)$ and category $2 \mathrm{D}\left(5.014 \mathrm{~m}^{2}\right)$. Figure $\underline{4 \mathrm{~b}}$ shows radiation distance for fireball and maximum radiation is $388 \mathrm{~kW} / \mathrm{m}^{2}$ at $8.66 \mathrm{~m}$. Figure $\underline{4 \mathrm{c}}$ displays explosion worst-case radii at downwind distance in category $2 \mathrm{~F}(721 \mathrm{~m})$, category 2B $(674 \mathrm{~m})$, category $2 \mathrm{D}(711 \mathrm{~m})$. In this scenario, the worst-case radius is at category $2 \mathrm{~F}$.
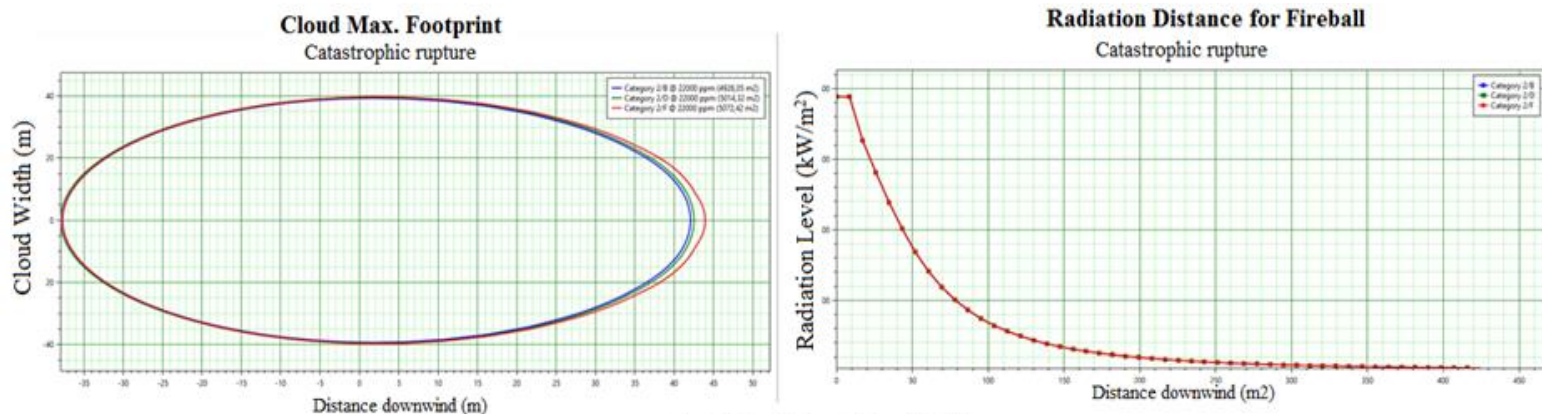

(a)

Explosion Worst Case Radii

(b)

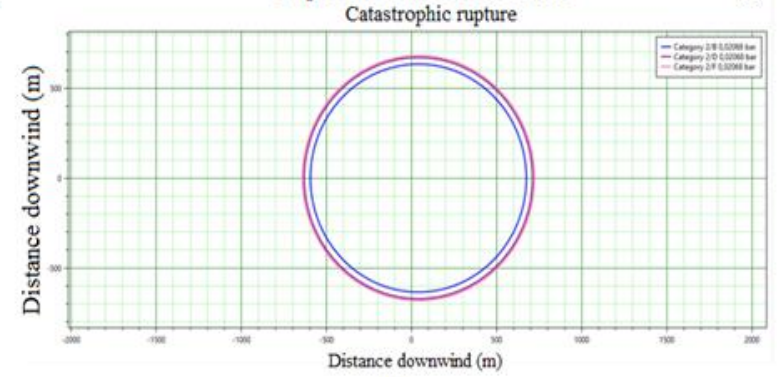

(c)

Figure 4. a) Maximum cloud footprint in case of catastrophic rupture; b) radiation distance for fireball; c) explosion worst-case radii

Combining the findings from ALOHA and PHAST provided us to analyse the location, layout and impact range of explosion and dispersion comprehensively. In case of the toxic effect area of vapour cloud in $2 \mathrm{~B}$ weather conditions, the explosion's worst influence range is approximately $25 \mathrm{~m}$ by ALOHA and $28 \mathrm{~m}$ by PHAST Software. The catastrophic rupture scenario is a model in which the tank is destroyed by a quick impact. According to the second scenario of PHAST, a large amount of energy $\left(388 \mathrm{~kW} / \mathrm{m}^{2}\right)$ is produced at $8.66 \mathrm{~m}$ for fireball case. 


\section{Conclusion}

Safety in biogas plants is very significant (Molnarne and Schroeder, 2019). The biogas production plants are known to be responsible for several accidents (Moreno and Cozzani, 2015; Schroder et al., 2014; Sasso, 2012). The European Commission has assessed the regions of the world that primarily use bioenergy and considers biogas to be a highly flammable mixture (Casson et al., 2016; Trávníček et al., 2018). The role of safety regulations should be revised and improved since there is a need for the statistical investigation of accidents, consequence modelling and analysis of explosions (Kotek et al. 2015). Although biogas tank explosions are not common, the results of such kind of explosions are very hazardous. (Boscolo et al., 2019; Casson et al., 2018; Trávníček et al., 2018). Pietrangeli et al. (2013) stated that the risk of explosion is particularly high close to overpressure safety devices like digesters and gasholders in a biogas plant. Therefore, in this study, preliminary calculations are carried out to explore effects of possible explosions in a large-scale industrial type biogas station.

According to the ALOHA software results of the leakage scenario from the biogas tank; the explosions may cause dangers like demolition of buildings at $74 \mathrm{~m}$ limit, serious injuries at $97 \mathrm{~m}$ limit and shattering of glasses at $184 \mathrm{~m}$ limit. In the examination of the flammable chemical spreading directly into the atmosphere, the destruction of buildings or serious injury likely will not happen but shattering of glasses will occur within the $22 \mathrm{~m}$ limit. Locations where the flammable chemical vapour lower explosion limit is $60 \%$ and $10 \%$ are observed in the range of 271 and $600 \mathrm{~m}$ respectively. In the first scenario of the PHAST software (leakage from the biogas storage tank), the studies performed in three different weather conditions give very close results and it is observed that the danger zone limits are lower than the first scenario of ALOHA. The second scenario of PHAST software belongs to a more serious catastrophic rupture, and the hazard zone limits are observed to be wider than all scenarios. When all the results are examined together, it has been observed that the use of software based on different models will be useful in estimating the impact areas of dangerous explosions that may be encountered in a biogas station.

The explosion modelling programs like ALOHA and PHAST will foresee the consequences of accidents (Hasani, 2016; Inanloo, 2015; Zareei, 2016). Several difficulties come out during the comparison of the models due to the differences in output values of different software. The geometrical effects of the programs contribute to differences between simulation tools. Buildings, terrain and geometry, in general, will have recirculation zones that will influence the local air movements. Despite the differences, the results of the programs used in this study will be useful for companies in emergency plans, fire departments, civil defence units of municipalities and governments. The explosion modelling software can be used for accident investigations. Another application area of these software could be the determination of dangerous and safe areas in biogas power plants. Thus in emergency drills, the workers could be informed about the determined dangerous areas and how to behave in case of an explosion. Several possible scenarios could be modelled without doing hazardous experiments.

\section{Acknowledgement}

This research did not receive any specific grant from funding agencies in the public, commercial, or not-forprofit sectors.

\section{Author Contributions}

Müge Ensari Özay: Collected data, designed study, performed software analysis and wrote the paper.

Peln Güzel: Collected data, performed software analysis and wrote the paper.

Emine Can: Conceived and designed the analysis. 


\section{Conflicts of Interest}

The authors declare no conflict of interest.

\section{References}

Al Seadi, T., Rutz, D., Prassl, H., Köttner, M., Finsterwalder, T., Volk, S., \& Janssen, R. (2008). Biogas Handbook, University of Southern Denmark Esbjerg, Denmark. Retrieved from https://www.lemvigbiogas.com/BiogasHandbook.pdf

Amyotte, P., \& Lupien, C. (2017). Different hazards, similar causes same results. Loss Prevention Bulletin, $253,14-18$.

Arıkan B., (2008). Organik Evsel Katı Atıklardan Anaerobik Ortamda Biyogaz Üretiminin Verimliliğinin Araştırılması. (Master's thesis). . Çukurova Üniversitesi, Adana, Turkey. Retrieved from: https://tez.yok.gov.tr/UlusalTezMerkezi/

Baker, Q.A., Tang, M.J., Scheier, E.A., \& Silva, G.J., (1996). Vapour cloud explosion analysis. Process Safety Progress, 15 (2), 106-109. DOI: https://doi.org/10.1002/prs.680150211

Bhattacharya, R., \& Ganesh Kumar, V. (2015). Consequence analysis for simulation of hazardous chemicals release using ALOHA software. International Journal of ChemTech Research, 8(4), 2038-2046.

Bilici, E. N., (2019). Occupational Health and Safety Management Systems Application in Biogas Plant, Master Thesis, Uskudar University. Retrieved from: https://tez.yok.gov.tr/UlusalTezMerkezi/

Boscolo, M., Bregant, L., Miani, S., Padoano, E., \& Piller, M. (2019). An enquiry into the causes of an explosion accident occurred in a biogas plant. Process Safety Progress, 12063. DOI: https://doi.org/10.1002/prs.12063

Carboni, M., Pio, G., Vianello, C., \& Salzano, E. (2020). Safety distances for the sour biogas in digestion plants. Process Safety And Environmental Protection, 147, 1-7. DOI: https://doi.org/10.1016/j.psep.2020.09.025

Casson, M. V., Papasidero, S., Scarponi, G. E., et al., (2016). Analysis of accidents in biogas production and upgrading. Renewable Energy, 96, 1127-1134. DOI: https://doi.org/10.1016/j.renene.2015.10.017

Çetinyokuş, S . (2017). Sonuç analizi ile belirlenen etki mesafeleri üzerine atmosferik seçimlerin etkisi (ALOHA yazılım1). Afyon Kocatepe Üniversitesi Fen ve Mühendislik Bilimleri Dergisi, 17 (1), 209217. DOI: https://doi.org/10.5578/fmbd.52776

Dadashzadeh, M., Khan, F., Hawboldt, K., \& Amyotte, P. (2013). An integrated approach for fire and explosion consequence modelling. Fire Safety Journal, 61, 324-337. DOI: https://doi.org/10.1016/j.firesaf.2013.09.015

Dasgotra, A., Varun Teja, G. V. V., Sharma, A., \& Mishra, K. B. (2018). CFD modelling of large-scale flammable cloud dispersion using FLACS. Journal of Loss Prevention in the Process Industries, 56, 531-536. DOI: https://doi.org/10.1016/j.jlp.2018.01.001

Davis, S. G., Engel, D., Gavelli, F., Hinze, P., \& Hansen, O. R. (2014). Advanced methods for determining the origin of vapor cloud explosions case study: The 2006 Danvers explosion investigation. Fire Technology, 50(4), 823-850. DOI: https://doi.org/10.1007/s10694-012-0305-6

Derychova, K., \& Bernatik, A. (2016, April). Risk assessment of biogas plants. Proceedings of the 1st International Conference on Applied Mathematics in Engineering and Reliability, Ho Chi Minh City, Vietnam. 
DNV GL., (2018). PHAST 3D Explosion Flier. Retrieved from: https://www.dnvgl.com/software/services/phast/phast-module-3d-explosions.html

Dou, Z., Zheng, L., Zheng, K., Pan, R.,Yang, W., \& Fu, Y., (2020). Effect of film thickness and methane fraction on explosion characteristics of biogas/air mixture in a duct. Process Safety and Environmental Protection, 139, 26-35. DOI: https://doi.org/10.1016/j.psep.2020.04.006

EPA. (2017). ALOHA Software. Retrieved from: https://www.epa.gov/cameo/aloha-software

Hasani F., \& Nader N., (2016). Consequence modelling and analysis of gas export compression unit using PHAST software, International Journal of Advanced Biotechnology and Research, 7 (5), 1344-1349.

Inanloo, B., \& Tansel, B. (2015). Explosion impacts during transport of hazardous cargo: GIS-based characterization of overpressure impacts and delineation of flammable zones for ammonia. Journal of Environmental Management, 156, 1-9. DOI: https://doi.org/10.1016/j.jenvman.2015.02.044

Kotek, L., Trávníček, P., \& Blecha, P. (2015). Accident analysis of european biogas stations. Chemical Engineering Transactions, 43, 1933-1938. DOI: https://doi.org/10.3303/CET1543323

Köse, T. E. (2017). Trakya bölgesinde hayvan gübrelerinin biyogaz enerji potansiyelinin belirlenmesi ve sayısal haritaların oluşturulması, Pamukkale Üniversitesi Mühendislik Bilim Dergisi, Denizli

Krentowski, J., \& Ziminski, K. (2019). Consequences of an incorrect assessment of a structure damaged by explosion. Engineering Failure Analysis, 101, 135-144. DOI: https://doi.org/10.1016/j.engfailanal.2019.03.009

Lee, H. E., Yoon, S. J., Sohn, J. R., Huh, D. A., Lee, B. W., \& Moon, K. W. (2019). Flammable substances in Korea considering the domino effect: Assessment of safety distance. International Journal of Environmental Research and Public Health, 16(6). DOI: https://doi.org/10.3390/ijerph16060969

Lv, D., Tan, W., Liu, L., Zhu, G., \& Peng, L. (2017). Research on maximum explosion overpressure in LNG storage tank areas. Journal of Loss Prevention in the Process Industries, 49, 162-170. DOI: https://doi.org/10.1016/j.jlp.2017.06.010

Mannan, M. S., (2012). Lees' Loss Prevention in the Process Industries: Hazard Identification, Assessment and Control. (4th ed.). Elsevier. DOI: https://doi.org/10.1016/C2009-0-24104-3

Molnarne, M., \& Schroeder, V. (2019). Hazardous properties of hydrogen and hydrogen containing fuel gases. Process Safety and Environmental Protection. 130, 1-5. DOI: https://doi.org/10.1016/j.psep.2019.07.012

Moreno, V.C., \& Cozzani, V., 2015. Major accident hazard in bioenergy production. Journal of Loss Prevention in the Process Industries, 35, 135-144. DOI: https://doi.org/10.1016/j.jlp.2015.04.004

Naemnezhad, A., Isari, A.A., Khayer, E. et al. (2017). Consequence assessment of separator explosion for an oil production platform in south of Iran with PHAST software. Modelling Earth Systems and Environment, 3, 43. DOI: https://doi-org.proxy.uskudar.edu.tr/10.1007/s40808-017-0297-9

Okho, P., \& Haugen, S. (2013). Maintenance-related major accidents: Classification of cause and case study. Journal of Loss Prevention and Process Industry, 26, 1060-1070. DOI: https://doi.org/10.1016/j.jlp.2013.04.002

Pandya, N., \& Marsden, E. (2008). Toxic release dispersion modelling with PHAST: Parametric sensitivity analysis. 3rd International Conference on Safety \& Environment in Process Industry, Italy.

Pietrangeli, B., Lauri, R., \& Bragatto, P. (2013). Safe operation of biogas plants in Italy. Chemical Engineering Transactions. 32, 199-204. DOI: https://doi.org/10.3303/CET1332034 
Yadav, R., Chaudhary, S., Yadav, B. P., Varadharajan, S., \& Tauseef, S. M. (2020). Assessment of Accidental Release of Ethanol and Its Dangerous Consequences Using ALOHA, Advances in Industrial Safety, Springer Singapore.

Sasso S., Laterza E., \& Valenzano. B. (2012). A Study about explosion hazards in presence of an uncontrolled anaerobic digestive process. Chemical Engineering Transactions, 26, 135-140. DOI: https://doi.org/10.3303/CET1226023

Schroder, V., Schalau, B., \& Molnarne, M. (2014). Explosion protection in biogas and hybrid power plants. Procedia Engineering, 84, 259-272. DOI: https://doi.org/10.1016/j.proeng.2014.10.433

Trávnícek, P., Kotek, L., Nejtek V., Koutný T., Junga P., \& Vítěz T. (2018). Quantitative analyses of biogas plant accidents in Europe. Renewable Energy, 122, 89-97. DOI: https://doi.org/10.1016/j.renene.2018.01.077

Tseng, J. M., Su, T. S., \& Kuo, C. Y. (2012). Consequence evaluation of toxic chemical releases by ALOHA. Procedia Engineering, 45, 384-389. DOI: https://doi.org/10.1016/j.proeng.2012.08.175

Van der Berg, A.C. (1985). The multi-energy method: A framework for vapour cloud explosion blast prediction. Journal of Hazardous Materials, 12, 1-10.

Wang, Y., Zhang, R., Zhang, Z., \& Wang, F. (2017). Leakage risk quantitative calculation model and its application for anaerobic reactor. Journal of the Taiwan Institute of Chemical Engineers, 77, 152-160. DOI: https://doi.org/10.1016/j.jtice.2017.04.038

Zareei, H., Nikou M. K., \& Shariati A. (2016). A consequence analysis of the explosion of spherical tanks containing liquefied petroleum gas (LPG). Iranian Journal of Oil \& Gas Science and Technology, 5 (3), $32-44$.

Zhang, Q., Zhou, G., Hu, Y., Wang, S., Sun, B., Yin, W., \& Guo, F. (2019). Risk evaluation and analysis of a gas tank explosion based on a vapor cloud explosion model: A case study. Engineering Failure Analysis, 101, 22-35. DOI: https://doi.org/10.1016/j.engfailanal.2019.03.003 